\title{
Obtenção de pellets por extrusão e esferonização farmacêutica. Parte II. Avaliação das características física de pellets
}

\author{
Helton Max Massaranduba Santos*, Francisco José Batista Veiga, Eugênica Maria Soares Tavares \\ de Pina, João José Martins Simões de Sousa
}

Universidade de Coimbra, Faculdade de Farmácia, Centro de Estudos Farmacêuticos

*Correspondence:

H. M.M. Santos

Centro de Estudos Farmacêuticos

Faculdade de Farmácia

Universidade de Coimbra

Rua do Norte, 3000295

Coimbra, Portugal

E-mail: helton@ci.uc.pt
O processo de peletização, abordado na Parte I, consiste na aglomeração por via úmida de pós de uma substância ativa e excipientes sob a forma de unidades esféricas denominadas por pellets. Os pellets diferem de grânulos não apenas pela técnica utilizada para a produção, mas também no que respeita as características físicas conseguidas. O presente trabalho, o segundo de uma série de dois, apresenta uma revisão das características fisicas e das técnicas para a caracterização física de pellets farmacêuticos abordando as principais necessidades posteriores a produção dessas multi-unidades, nomeadamente revestimento com película, enchimento de cápsulas, compressão, manuseamento, armazenamento e transporte.
Uniterms

- Caracterização física

- Pellets

- Peletização

- Esferas

\section{INTRODUÇÃO}

O processo de produção de pellets, denominado de peletização, anteriormente descrito, consiste na aglomeração de pós finos contendo a(s) substância(s) ativa(s) e os excipientes em pequenas unidades esféricas denominadas de pellets. É devido ao crescente interesse que os pellets têm despertado na tecnologia farmacêutica que se faz necessária uma correta avaliação e caracterização física dessas multi-unidades para um posterior processamento, transporte e armazenamento. Apenas através da avaliação das características físicas dos pellets é possível aprovar a viabilidade de uma formulação e/ou do processo empregado para a produção.

A primeira parte deste trabalho abordou as implicações das variáveis de formulação e dos parâmetros de processo sobre a produção de pellets (Santos et al., 2004). A segunda parte do trabalho aqui apresentada oferece uma revisão da literatura sobre as características físicas de pellets e as diferentes técnicas de determinação destas características levando-se em consideração possíveis processamentos posteriores a produção, o armazenamento e o transporte dessas multi-unidades.

Diversas características de pellets podem ser avaliadas com o intuito de controle de qualidade, avaliação do processo de produção ou da viabilidade de uma formulação. Dentre as diversas características pode-se citar: tamanho e distribuição de tamanho, densidade aparente e real, massas volúmicas em bruto e reduzida, área superficial externa, esfericidade, morfologia superficial, propriedades de empacotamento, resistência à fratura e friabilidade.

\section{TAMANHO DE PELLETS}

O tamanho dos pellets tem efeito direto sobre a área superficial. É portanto necessário o uso de partículas com distribuição uniforme de tamanho para a obtenção de um produto final de desempenho uniforme. 
Uma distribuição uniforme de tamanho facilita a mistura de pellets sobretudo quando há a necessidade de se misturar pellets de diferentes lotes ou de diferentes composições para o enchimento de cápsulas ou a produção de comprimidos de pellets. A distribuição uniforme de tamanho de pellets tem o propósito de evitar segregação e consequente variação do conteúdo de substância ativa e de sua biodisponibilidade. Este parâmetro torna-se de grande relevância quando se pretende considerar o revestimento de pellets por filme seja com o intuito de proteção entérica, liberação modificada da substância ativa, mascaramento do sabor ou simplesmente por uma questão estética (Mehta, 1989). Assim, é fundamental assegurar o mínimo de variação da espessura da película de revestimento para um lote de pellets uma vez que o tamanho da unidade tem relação direta com a área superficial que por sua vez influencia a quantidade de material de revestimento necessária para a cobertura completa e uniforme das multiunidades indispensável para uma biodisponibilidade invariável.

A determinação da distribuição de tamanho pode ser realizada por diferentes métodos, nomeadamente a tamização, a microscopia (óptica ou eletrônica) e a análise por imagens.

A tamização de pellets é o método mais vulgarmente utilizado e que permite a separação das diferentes frações de tamanho de unidades. O uso corrente deste método deve-se ao seu baixo custo, simplicidade, rapidez e baixa variação na determinação por diferentes operadores (Mehta, 1989). Três tipos de padrões de tamises podem ser utilizados: o padrão americano, o padrão Tyler e o padrão britânico. É necessário que no processo de tamização as variáveis críticas sejam padronizadas, designadamente a carga para tamização, o tipo de movimento (vibratório ou pancada), a intensidade e a duração da agitação.

A microscopia e a análise por imagem são métodos diretos de determinação. Na microscopia óptica o diâmetro dos pellets pode ser determinado por meio de um filete calibrado ou por meio de lâminas de grelhas circulares ou quadradas. Para a microscopia eletrônica, as amostras devem ser revestidas com uma película apropriada para a observação (p.ex., ouro ou ouropaládio). A desvantagem para ambas as técnicas é o fato de serem cansativas uma vez que consomem muito tempo para a observação individualizada de um grande número de pellets necessário para a criação dos gráficos de frequência da distribuição de tamanho e de percentagem acumulada (Mehta, 1989).

O tamanho de pellets também pode ser determinado por um instrumento medidor de tamanho com abertura em forma de anel (ring gap sizer). Esta técnica foi utilizada em trabalhos publicados por Nyström e Stanley-Woods (1976), Nyström e Stanley-Woods (1977), Nyström e Malmqvist (1977).

Um outro método utilizado com o propósito da determinação do tamanho de pellets é a análise por imagens assistida por um programa de computador. Este método assemelha-se à microscopia óptica requerendo, no entanto, a utilização de um sistema óptico de captura de imagens dotado de uma câmara de vídeo e um microscópio ou sistema de lentes de aumento interligados a um sistema computadorizado (Fielden et al., 1993; Hellén et al., 1993a, b; Wan et al., 1993; Lindner, Kleinebudde, 1994; Newton et al., 2001, Santos et al., 2002, 2004, 2005). Este mesmo sistema também pode ser utilizado com o propósito de determinação de parâmetros de esfericidade de pellets e será descrito adiante. Esta técnica requer a utilização de uma quantidade de amostras semelhante à empregada na microscopia tendo a vantagem de ser menos cansativa.

\section{DENSIDADE DE PARTÍCULAS}

A densidade é uma característica relevante para estas multi-unidades, uma vez que pode ser alterada por fatores de formulação e/ou de processo. Salienta-se que a densidade dos pellets terá influência sobre parâmetros de processo posteriores a produção e sobre a biodisponibilidade da substância ativa (Devereux et al., 1990; Clarke et al., 1993).

Os pellets são habitualmente destinados ao enchimento de cápsulas ou à compressão com a finalidade de servirem como formas farmacêuticas de unidades múltiplas. Por este motivo torna-se imperativo que a densidade dessas unidades varie minimamente quando na utilização de lotes diferentes para os processos mencionados. Uma alta variação entre lotes acarretará numa grande variabilidade quer do enchimento de cápsulas quer da produção de comprimidos com consequente variabilidade de conteúdo de substância ativa afetando, desta forma, a biodisponibilidade. Igual atenção deve ser tomada quando se pretende realizar a mistura de pellets de diferentes composições para posterior enchimento de cápsulas ou compressão (Mehta, 1989).

Um outro fator que deve ser considerado é o revestimento de pellets. Uma grande variação da densidade de pellets conduz à uma grande variação do tamanho de lote destinado ao processo de revestimento e, consequentemente, na quantidade de material a ser empregado naquele processo. Portanto, é fundamental que, para um posterior processamento de pellets, traba- 
lhe-se com unidades de densidades próximas e que a densidade seja reprodutível entre lotes.

As massas volúmicas em bruto (antes de compactação por batimento) e reduzido (após compactação por batimento) de pellets podem ser determinadas pelo método clássico descrito em diferentes farmacopéias (p.ex., Farmacopeia Portuguesa VII) utilizandose um aparelho de compactação que promova batimentos para determinação desses parâmetros. A massa volúmica do produto em bruto, que consiste apenas no volume ocupado por uma massa de pellets sem qualquer batimento para acomodação da coluna de material, é uma característica indicativa de propriedades de empacotamento das unidades e por isso será extremamente influenciada pelo volume e tamanho das unidades individuais e pela esfericidade.

A densidade pode ser determinada por picnometria gasosa, utilizando ar ou hélio como gás de intrusão, ou pelo método de deslocamento de um líquido. A determinação da densidade utilizando-se um picnômetro com hélio como gás de intrusão é a mais utilizada visto que o hélio penetra nos poros de menor tamanho e nas fissuras resultando num valor mais aproximado da densidade verdadeira do material. O resultado desta determinação inclui o volume de poros fechados no interior dos pellets sendo normalmente referida como densidade aparente. A densidade verdadeira do material pode ser determinada se o volume dos poros fechados é excluído do resultado obtido por picnometria (Martin, 1993; Vertommen et al., 1998).

A densidade também pode ser determinada pelo método de intrusão do mercúrio sob pressão. A técnica por intrusão de mercúrio é utilizada não apenas para a determinação da densidade de pellets mas também para se obter informações acerca das características porosas do material sólido. Como conseqüência da comportamento não molhante do mercúrio, faz-se necessária a aplicação de alta pressão para forçar a intrusão do mercúrio nos mais pequenos poros. Desta forma um amplo intervalo de poros pode ser penetrado consoante o tipo de aparelho, assim esta técnica mostra-se extremamente adequada para materiais com ampla distribuição de poros ou principalmente macroporos. Vários aparelhos para a determinação da densidade pela intrusão de mercúrio estão disponíveis no mercado. No entanto, apesar destes aparelhos proporcionarem a aplicação de altas pressões, deve-se ter em atenção à pressão aplicada sobre os pellets visto que uma pressão demasiado alta pode ocasionar a compressão das multi-unidades e resultar no colapso de poros fechados levando a falsos resultados (Schröder, Kleinebudden 1995; Vertommen et al., 1998).

\section{POROSIDADE}

Porosidade é a medida de espaços vazios existentes num material e pode ser determinada por diversas técnicas: adsorção gasosa, deslocamento de um líquido, porosimetria ou por cálculo matemático a partir das densidades. A determinação da porosidade de um material sólido pode fornecer informações relevantes sobre a desagregação das multi-unidades, dissolução, adsorção e difusão de substâncias ativas.

No que se refere especificamente aos pellets, a determinação da porosidade é um importante fator a ser avaliado visto que esta propriedade pode afetar a capilaridade da substância ativa dissolvido durante a dissolução e assim influenciar a razão de liberação da substância ativa incorporada à formulação. Outro fator relevante diz respeito ao processo de revestimento de pellets por película. Neste caso, os poros e fissuras superficiais podem influenciar o depósito do material de revestimento, ocasionar imperfeições e irregularidades e consequente variabilidade da performance biológica destas unidades (Metha, 1989).

A medida do tamanho de poros proporciona a obtenção de informações acerca da estrutura porosa do material. As informações sobre os tamanhos dos poros de um material são obtidas num intrumento que permite a condensação de um gás inerte (p.ex., nitrogênio) nos poros do material e o cálculo do volume dos poros através das quantidades de gás necessárias para preencher os poros. Esta análise é normalmente realizada em conjunto com a análise de áreas superficiais. No entanto, no caso de uma análise de porosimetria, o instrumento não é interrompido quando ocorre a formação da primeira camada de gás adsorvido necessária para a determinação da área superficial. Ao contrário, o instrumento continua a preencher o material com o gás até que se inicie a sua condensação. O método de porosimetria por intrusão de mercúrio é mais rápido que a análise por adsorção gasosa. O intervalo de medida de diâmetro de poros é de $0,0015 \mu \mathrm{m}-360 \mu \mathrm{m}$ (consoante o tipo de aparelho). Uma vez que esta técnica pode alcançar os 60000 psi e utiliza o mercúrio, nem todos os materiais podem por ela ser analisados. As informações sobre os poros são obtidas pelo preenchimento forçado de mercúrio líquido através do aumento da pressão externa. Ao passo que a pressão é aumentada, registra-se a quantidade de mercúrio necessária para o preenchimento dos poros. Esta informação, juntamente com a informação sobre o ângulo de contato do mercúrio, é utilizada para a determinação da estrutura porosa (Palmer, Rowe, 1974; Carli, Motta, 1984). 
A porosimetria com mercúrio tem sido amplamente empregada na tecnologia farmacêutica para a determinação da porosidade de grânulos (Fujiwara et al., 1966; Juppo, Yliruusi, 1994; Zuurman et al., 1994; Juppo, 1996 a, b), de comprimidos (Carli et al., 1981; Wikberg, Alderborn, 1990; Wikberg, Alderborn, 1992; Mattsson, Nyström, 2001) e de pós (Palmer, Rowe, 1974; Carli, Motta, 1984; Mattsson, Nyström, 2001). Também permite a determinação da distribuição de tamanho dos poros, a densidade do material em análise e a área superficial específica (Martin, 1993).

\section{ÁREA SUPERFICIAL}

A área superficial específica por unidade de massa ou de volume de uma amostra é uma importante propriedade que deve ser considerada, sobretudo quando se pretende realizar estudos de adsorção superficial ou de dissolução (Martin, 1993). Tratando-se de pellets, deve-se ter em consideração que esta propriedade é influenciada direta ou inversamente pelo tamanho das unidades, pela forma ou esfericidade, pela porosidade e pela rugosidade ou aspereza superficial (Mehta, 1989).

O conhecimento da área superficial de pellets torna-se sobremaneira importante quando se pretende realizar o revestimento dessas unidades. Assim, qualquer característica morfológica dos pellets desempenhará uma importante influência sobre a área superficial disponível para o revestimento. Como consequência disto, poderá haver variação da liberação da substância ativa em virtude de uma variação significativa da área superficial inter-lotes que proporciona diferenças igualmente significativas da espessura da película de revestimento das unidades.

Diferentes técnicas para a determinação da área superficial de materias sólidos são sugeridas pela literatura (Mehta, 1989; Martin, 1993). O método matemático permite o cálculo da área superficial de uma amostra a partir do conhecimento da distribuição do tamanho de partículas determinada por meio de qualquer uma das técnicas descritas anteriormente. Neste caso, o cálculo da área superficial de pellets pode ser realizado por intermédio do diâmetro médio das unidades ou da densidade aparente. Duas outras técnicas são usualmente utilizadas para a determinação direta da área superficial de materiais sólidos. A primeira técnica, adsorção gasosa ou líquida, baseia-se no princípio de que a quantidade de um soluto gasoso ou líquido fisicamente adsorvido sobre a superfície de uma amostra para formar um mono camada é uma função direta da sua área superficial. A quantidade de gás adsorvido (p.ex., nitrogênio ou criptônio) pode ser determinada por gravimetria, volumetria ou por uma técnica de fluxo contínuo. Antes de qualquer determinação de área superficial faz-se necessário a remoção de gases ou de vapores adsorvidos na superfície do sólido durante o seu processamento, manuseio ou armazenamento. A remoção desses gases ou vapores tem por objetivo evitar a redução ou variação da área superficial decorrente de uma prévia ocupação da superfície por outras moléculas. As condições de temperatura, pressão e tempo para a remoção de gás ou vapor adsorvido devem ser bem definidas a fim de que a determinação da área superficial da amostra seja reproduzida com máxima fidelidade. A medida da adsorção do gás é realizada a baixa temperatura uma vez que a quantidade de gás adsorvido numa dada pressão tende a baixar ou aumentar a temperatura durante o ensaio. Os dados gerados pela determinação são tratados de acordo com a conhecida função de Brunauer, Emmett e Teller (BET).

O segundo método, permeabilidade gasosa ou líquida, baseia-se no fato de que a razão na qual um gás ou líquido permeia o leito do material sólido está relacionada com a área superficial exposta àquele meio. Devido à sua simplicidade e rapidez, este método é aplicável no controle de qualidade de um produto com o propósito de evitar variações inter-lotes. A área superficial de uma amostra é determinada a partir da resistência do material compactado ao fluxo de um fluido líquido ou gasoso. São encontradas diversas referências à aplicação deste método na determinação da área superficial de pellets (Johansson et al., 1995; Johansson et al.,1998; Nicklasson et al., 1999a; Nicklasson et al., 1999b; Johansson, Alderborn, 2001).

\section{ESFERICIDADE}

Os pellets destinam-se usualmente ao revestimento com filme embora estas unidades também possam ser formuladas sob a forma de sistemas matriciais. Em qualquer um dos casos torna-se importante a determinação da esfericidade e rugosidade superficial destes aglomerados. Para o revestimento com filme, a forma esférica dos pellets permite as condições ideais para a aplicação uniforme da película de revestimento desde que seja garantida uma superfície relativamente ausente de imperfeições. A forma esférica dos pellets desempenha um importante papel nas propriedades de empacotamento e de escoamento, propriedades que terão grande influência num posterior processo de enchimento de cápsulas ou de compressão. Assim, não apenas a esfericidade dos pellets mas também a morfologia 
superficial devem ser mantidas entre limites predeterminados para garantir uma reprodutibilidade na produção de uma forma farmacêutica. Por este motivo, um método adequado para a determinação e descrição da esfericidade e da rugosidade de superfície de pellets deve ser suficientemente sensível para distinguir pequenas variações destas características durante o processo de produção da forma farmacêutica.

Yliruusi et al. (1992) desenvolveram e compararam cerca de vinte fatores de esfericidade sem, no entanto, apresentarem resultados conclusivos e satisfatórios. Um fator comumente usado para a descrição da esfericidade de pellets é o aspect ratio (Scheneiderhöhn, 1954). Este fator é definido como a razão entre a maior distância de uma partícula (comprimento) e sua dimensão perpendicular (profundidade). Contudo, este fator apresenta algumas limitações visto que não distingue entre círculo, quadrado ou qualquer outro polígono de forma simétrica que apresenta comprimento e profundidade iguais. Outro fator igualmente de grande utilização é o fator de alongamento (elongation factor) que é definido como a razão entre o menor diâmetro de Feret e o diâmetro de Feret perpendicular a este (Tsubaki, Jimbo, 1979). O diâmetro de Feret de um pellet é definido como a distância média de 36 medidas por volta da partícula empregando-se um ângulo de rotação de $5^{\circ}$. A utilização destes fatores de esfericidade encontra opiniões divergentes na literatura científica. Beddow (1983) concluiu que o aspect ratio e a razão de alongamento não refletem com exatidão uma esfericidade e, por este motivo, devem ser evitadas. Porém, Lindner, Kleinebudde (1993) concluíram que estes dois fatores, o aspect ratio e a razão de alongamento, são matematicamente equivalentes tendo em consideração a determinação apenas para esferóides.

Um outro fator utilizado para descrever a esfericidade de partículas esferóides é a circularidade. Este fator foi primeiramente definido por Cox (1927) e depois redefinido por Hausner (1966). Contudo, e semelhantemente aos fatores anteriormente mencionados, a circularidade mostra-se limitada para a caracterização de esfericidade já que não permite diferenciar esferas de diferentes figuras poligonais simétricas. A circularidade $(C)$ é calculada segundo a Equação 1.

$$
C=\frac{4 \pi A}{P^{2}} \quad \text { Equação } 1
$$

Onde $A$ é a área projetada da linha de perfil bidimensional da partícula, e $P$ é o perímetro da linha de perfil. A esfericidade projetada $(P S)$, um outro fator de esfericidade inicialmente definido por Pentland (1927), é calculada pela Equação 2.

$$
P S=\frac{4 A}{\pi d_{L}^{2}} \quad \text { Equação } 2
$$

Onde $d_{L}$ é a maior distância observada na análise da partícula.

Chapman et al. (1988) propõem como fator de esfericidade a estabilidade planar crítica (one-plane critical stability) como sendo capaz de diferenciar pequenos desvios de esfericidade em partículas esferóides. Este fator tem encontrado grande aceitação, no entanto a sua utilização requer um sistema computadorizado adequado e licenciado tendo como desvantagem o fato de ser uma técnica cansativa por envolver a determinação individual do fator de esfericidade para cada partícula.

Diversos fatores de esfericidade podem ser obtidos utilizando-se a técnica de análise de imagem (Podczeck, Newton, 1994, 1995; Podczeck et al., 1999; Chopra et al., 2001). Podczeck e Newton (1994) propõem o fator de esfericidade $e_{R}$ determinado a partir de análise de imagens bidimensionais. Este fator mostra-se de grande importância pois distingue-se dos anteriormente mencionados por ser capaz de diferenciar partículas esferóides de outras partículas poligonais simétricas com a vantagem de conjugar num único fator a forma da partícula com as suas características morfológicas superficiais. Em sequência deste estudo, Podczeck e Newton (1995) desenvolveram o conceito de fator de esfericidade $e_{c 3}$ para a caracterização da qualidade de pellets baseado em análise de imagens tridimensionais. $\mathrm{O}$ fator de esfericidade $e_{c 3}$ mostra-se capaz de diferenciar lotes de pellets não diferenciados por outras técnicas.

O fator de esfericidade $e_{R}$ é definido pela Equação 3.

$$
e_{R}=\frac{2 \pi r_{e}}{P f}-\sqrt{1-\left(\frac{b}{l}\right)^{2}} \quad \text { Equação } 3
$$

Onde $r_{e}$ é o raio médio derivado pela medida de 72 distâncias entre o centro de gravidade da linha de perfil bidimensional da partícula e o perímetro utilizando-se um ângulo de rotação de $5^{\circ}$ entre cada linha. $b$ e $l$ são, respectivamente, o comprimento e a largura da linha de perfil bidimensional da partícula. $f$ o fator de correção introduzido por Podczeck e Newton (1995) e definido pela Equação 4.

$$
f=1,008-0,231\left(1-\frac{b}{l}\right) \quad \text { Equação } 4
$$

Para o fator de esfericidade $e_{R}$, o valor de uma unidade é considerado para uma esfera perfeita embora um 
valor próximo ou superior a 0,6 caracteriza uma partícula de boa esfericidade.

\section{RUGOSIDADE DE SUPERFÍCIE}

Tal como salientado anteriormente, a determinação das características superficiais de aglomerados é de grande importância no controle de qualidade destas partículas para um posterior processamento. A morfologia superficial de pellets irá afetar outras propriedades, nomeadamente as propriedades de empacotamento e de escoamento. Assim, a rugosidade de superfície representa um fator relevante no que diz respeito aos processos de enchimento de cápsulas e de compressão. Esta característica terá igual relevância no revestimento de pellets com filme onde é imperativa a obtenção de aglomerados com superfície regular que servirão de suporte para uma camada de revestimento regular, imprescindível para a proteção (no caso de uma proteção entérica) ou para liberação uniforme da substância ativa.

As microscopias óptica e eletrônica são técnicas normalmente utilizadas na caracterização da morfologia superficial de pellets possibilitando a obtenção de imagens de boa resolução. Contudo, estas técnicas produzem apenas informações qualitativas sobre a rugosidade ou aspereza da superfície. Por outro lado, a profilometria é uma técnica que permite a quantificação a partir da determinação de um fator de rugosidade de superfície. A profilometria de contato efetua-se com um profilômetro dotado de uma extremidade pontiaguda para traçar a superfície do sólido produzindo, assim, movimentos verticais que são convertidos num sinal elétrico que é então integrado como um fator de rugosidade de superfície. Contudo, a profilometria de contato tem como inconveniente a limitação da resolução da técnica pela dimensão da agulha que pode não ter acesso a determinadas zonas superficiais e assim levar à subvalorização do fator de rugosidade além de poder danificar a superfície em contato. A profilometria a laser mostra-se superior à de contato visto que permite uma maior resolução com resultados fiáveis não havendo o contato direto de qualquer objeto pontiagudo com a superfície do sólido o que evita a danificação da superfície. Esta técnica tem sido aplicada na avaliação de pellets e comprimidos de pellets como meio de comparação das diferenças na rugosidade (Podczeck, 1998; Riippi et al., 1998; Newton et al., 2001; Santos et al., 2002, 2004, 2005).

Diversos parâmetros de rugosidade de superfície são apresentados (Figura 1, Quadro 1):

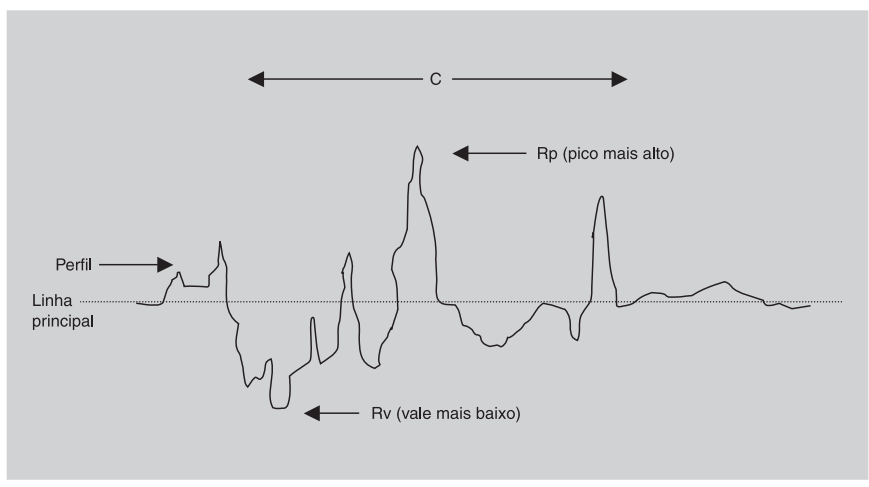

FIGURA 1 - Representação de uma linha de perfil de varredura de superfície.

QUADRO 1 - Parâmetros de rugosidade de superfície

Ra (arithmetic mean roughness)

$R q$ ou $R M S$ (root mean square roughness)

Rt (largest measured value)

Rtm

$R p$

$R z$ (ten-point height)
É a média aritmética de rugosidade. Também denominado por linha central média (central line average). Corresponde ao desvio médio de um traço de perfil da linha principal da varredura de uma superfície. Quando a técnica permite a obtenção de um perfil tridimensional da área varrida, $R a$ será a média aritmética dos valores absolutos de todos os pontos do perfil obtido.

É o desvio padrão da distribuição das alturas de um perfil de varredura de uma superfície.

É o maior valor medido correspondente à soma do maior pico e do vale mais baixo de um perfil de varredura de uma superfície.

É a media aritmética da diferença das alturas maiores $(R t)$ em 25 rectângulos obtidos quando se divide a superfície de varredura numa grelha do tipo $5 \times 5$. É considerado o parâmetro de rugosidade de superfície de maior importância.

É a diferença entre o valor da maior e da menor medida.

É a média da diferença de altura entre os cinco picos mais altos e os cinco vales mais profundos de um perfil de varredura de uma superfície. 


\section{PROPRIEDADES MECÂNICAS}

Não diferente de outras formas farmacêuticas, os pellets devem possuir características físicas que suportem um subsequente processamento, manipulação, transporte e armazenamento. Normalmente os pellets por si não são utilizados como uma forma final mas são acondicionados em cápsulas de gelatina ou, mais recentemente, são compactados sob a forma de comprimidos. Para os pellets que se destinam ao processo de revestimento com filme e/ou aos processos de enchimento de cápsulas ou compressão direta, é indispensável que as multi-unidades possuam boas características mecânicas, nomeadamente friabilidade e dureza.

A friabilidade, definida como o fenômeno pelo qual a superfície de uma amostra é danificada ou apresenta sinais de abrasão ou de ruptura devido a choques mecânicos ou ao atrito é normalmente determinada sob a forma de índice de friabilidade utilizando-se um friabilômetro e uma técnica adaptada a pellets. Alguns autores citam que a determinação de um índice de friabilidade deve ser realizada em condições que melhor expressem as condições nas quais os pellets serão eventualmente submetidos (Wan, Jeyabalan, 1986). A friabilidade de pellets que serão submetidos a revestimento numa bacia ou numa câmara de leito fluidificado, pode ser determinada nestes mesmos equipamentos tendo-se em consideração as variáveis tempo, massa do sólido e qualquer outra variável relevante. Wan e Jeyabalan (1986) determinaram a friabilidade de pellets num friabilômetro na presença de esferas de aço. Alternativamente pode-se utilizar esferas de vidro.

A dureza constitui uma designação dada à resistência de sólidos compactados ou aglomerados em termos de força necessária para promover a sua fratura. No entanto, o termo que melhor se aplica a esta definição é a resistência mecânica uma vez que esta determinação não considera o modo como a ruptura se processa ou as dimensões da amostra. Especificamente para pellets, a determinação da resistência tênsil aplica-se à caracterização da resistência mecânica dessas unidades. Com esta finalidade, os pellets são pressionados até o registro da fratura. Shipway e Hutchings (1993) desenvolveram uma equação (Equação 6) para a determinação da tensão superficial em volta do equador de pellets que se baseia em fundamentos teóricos que se provam experimentalmente válidos (Salako et al., 1998).

A resistência de pellets à fratura pode ser determinada utilizando um instrumento de teste universal equipado com uma célula de carga definida (p.ex., CT-5, Engineering Systems, Nottingham, UK). Os pellets são pressionados até a detecção da primeira fratura. No que respeita a utilização de pellets, faz-se necessário que haja a distinção entre o desenvolvimento de uma tensão interna e uma tensão superficial. Estes dois tipos de tensões são desenvolvidas simultaneamente e resultam no colapso tênsil da unidade de pellet quando esta é pressionada. A tensão interna é normalmente uma aproximação de uma relação empiricamente estabelecida (Hiramatsu, Oka, 1966; Darvell, 1990; Sikong et al., 1990) e definida pela Equação 5.

$$
\sigma_{f}(i) \approx \frac{0,7 F}{\pi R^{2}} \quad \text { Equação } 5
$$

Onde $\sigma_{f}(i)$ é a tensão interna, $F$ é a força de colapso, e $R$ é o raio do pellet.

No entanto, a Equação 5 torna-se inválida se as superfícies do instrumento de teste são demasiado duras que não são deformadas pela unidade de pellet que é a única entidade que deforma duração a compressão. Neste caso, a tensão interna é subestimada (Hutchings, 1996). Por outro lado, a tensão superficial no equador da unidade esférica é independente da deformação da superfície do instrumento podendo-se assim aplicar a equação definida por Shipway e Hutchings (1993):

$$
\sigma_{f}(s)=\frac{0,4 F}{\pi R^{2}} \quad \text { Equação } 6
$$

Onde, $\sigma_{f}(\mathrm{~s})$ a tensão superficial, $F$ é a força de fratura, $R$ é o raio médio dos pellets. O raio médio pode ser aquele determinado por análise por imagem (diâmetro de Feret).

A carga de fratura é registrada e a tensão é calculada de acordo com a Equação 6 (Shipway, Hutchings, 1993; Salako et al., 1998).

\section{AGRADECIMENTOS}

Helton Santos agradece à Fundação Para a Ciência e a Tecnologia, Portugal, o apoio financeiro sob a forma da bolsa de doutoramento BD/18171/98.

\section{ABSTRACT}

\section{Production of pellets by pharmaceutical extrusion and spheronisation. Part II. Physical characterisation of pellets}

The pelletisation process described in Part I consists of the wet agglomeration of fine powders of a drug substance and excipients into spherical units referred as pellets. Pellets differ from granules in terms of the production process and the physical characteristics. The current 
work, the second part of a series of two, intends to describe and revise the literature of the evaluation and characterisation of active drug pellets regarding the needs of postproduction of the units namely, film coating, capsule filling, compression, handling, storing and shiping.

UNITERMS: Physical characterisation. Pellets. Pelletisation. Sphere.

\section{REFERÊNCIAS BIBLIOGRÁFICAS}

BEDDOW, J.K. Morphological analysis, ten years of progress. Particle Sci. Technol., v.1, p.101-123, 1983.

CARLI, F.; COLOMBO, I.; SIMIONI, L.; BIANCHINE, L.; BIANCHINE, R. The effect of compression on the capillary microstructure of tablets. J. Pharm. Pharmacol., v.33, p.129-135, 1981.

CARLI, F.; MOTTA, A. Particle size and surface area distributions of pharmaceutical powders by microcomputerized mercuryporosimetry. J. Pharm. Sci., v.73, p.197-203, 1984.

CHAPMAN, S.R.; ROWE, R.C.; NEWTON, J.M. Characterisation of the sphericity of particles by the one plane critical stability.J. Pharm. Pharmacol., v.40, p.503$505,1988$.

CHOPRA, R.; NEWTON, J.M.; ALDERBORN, G.; PODCZECK, F. Preparation of pellets of different shape and their characterization. Pharm. Dev. Technol., v.6, p.495-503, 2001.

CLARK, G.M.; NEWTON, J.M.; SHORT, M.D. Gastrointestinal transit of pellets of differing size and density. Int. J. Pharm., v.100, p.81.92, 1993.

COX, E.P. A method of assigning numerical and percentage values to the degree of roundness. J. Paleontol., v.1, p.179-183, 1927.

DEVEREUX, J.E.; NEWTON, J.M.; SHORT, M.B. The influence of density on the gastrointestinal transit of pellets. J. Pharm. Pharmacol., v.42, p.500-501, 1990.

FIELDEN, K.E.; NEWTON, J.M.; ROWE, R.C. The influence of moisture content on spheronisation of extrudate processed by a ram extruder. Int. J. Pharm., v.97, p.79-92, 1993.
FUJIWARA, H.; TODA, J.; KATO, M. Studies on pore structure of granules by mercury porosimetry. Chem. Pharm. Bulletin, v.14, p.601-607, 1966.

HAUSNER, H.H. Characterisation of the powder particle shape. Planseeber. Pulvermet., v.14, p.75-84, 1966.

HELLÉN, L.; YLIRUUSI, J.; KRISTOFFERSSON, E. Process variable of instant granulator and spheroniser: II. Size and size distributions of pellets. Int J. Pharm., v.96, p.205-216, 1993a.

HELLÉN, L.; YLIRUUSI, J.; MUTTONEN, E.; KRISTOFFERSSON, E. Process variable of the radial screen extruder: II. Size and size distributions of pellets. Pharm. Tech. Int., v.5, p.44-53, 1993 b.

HUTCHINGS, I.M. Deformation and fracture of brittle particles. In: ADAMS, M.J.; BISWAS, S.K.; BRISCOE, B.J. (Eds.), Solid-Solid Interactions. London: Imperial College Press, 1996. p. 211-224.

JOHANSSON, B.; ALDERBORN, G. The effect of shape and porosity on the compression behaviour and tablet forming ability of granular materials formed from microcrystalline cellulose. Eur. J. Pharm. Biopharm., v.52, p.347-357, 2001.

JOHANSSON, B.; NICKLASSON, F.; ALDERBORN, G. Effect of pellet size on degree of deformation and densification during compression and on compactability of microcrystalline cellulose pellets. Int. J. Pharm., v.163, p.35-48, 1998.

JOHANSSON, B.; WIKBERG, M.; EK, R.,ALDERBORN, G. Compression behaviour and compactability of microcrystalline cellulose pellets in relation to their pore structure and mechanical properties. Int. J. Pharm., v.117, p.57-73, 1995.

JUPPO, A.M. Porosity parameters of lactose, glucose and mannitol granules obtained by mercury porosimetry. Int J. Pharm., v.129, p.1-12, 1996a.

JUPPO, A.M. Change in porosity parameters of lactose, glucose and mannitol granules caused by low compression force. Int. J. Pharm., v.130, p.149-157, 1996 b.

JUPPO,A.M.; YLIRUUSI, J. Effect of amount of granulation liquid on total pore volume and pore size distrinution of lactose, glucose and mannitol granules. Eur. J. Pharm. Biopharm., v.40, p. 299-309, 1994. 
LINDNER, H.; KLEINEBUDDE, P. Anwendung der automatischen bildanalyse zur charakterisierung von pellets. Pharm. Ind., v.55, p.694-701, 1993.

LINDNER, H.; KLEINEBUDDE, P. Use of powdered cellulose for production of pellets by extrusion/ spheronisation. J. Pharm. Pharmacol., v.46, p.2-7, 1994.

MARTIN, A.N. Physical Pharmacy. 4th ed., Philadelphia: Lea \& Febiger, 1993. 622pp.

MATTSSON, S.; NYSTRÖM, C. The use of mercury porosimetry in assessing the effect of different binders on the pore structure and bonding properties of pellets. Eur. J. Pharm. Biopharm., v.52, p.237-247, 2001.

MEHTA,A.M. Evaluation and characterization of pellets. In: GHEBRE-SELLASSIE, I. Ed., Pharmaceutical pelletization technology., New York: Marcel Dekker Inc., 1989. p.241-266.

NEWTON, J.M.; PETERSSON, J.; PODCZECK, F.; CLARKE, A.; BOOTH, S. The influence of formulation variables on the properties of pellets containing a selfemulsifying mixture. J. Pharm. Sci., v.90, p.987-995, 2001.

NICKLASSON, F.; JOHANSSON, B.; ALDERBORN, G. Occurrence of fragmentation during compression of pellets prepared from a 4 to 1 mixture of dicalcium phosphate dehydrate and microcrystalline cellulose. Eur. J. Pharm. Sci., v.7, p.221-229. 1999a.

NICKLASSON, F.; JOHANSSON, B.; ALDERBORN, G. Tabetting behaviour of pellets of a series of porosities a comparison between pellets of two different compositions. Eur. J. Pharm. Sci., v.8, p.11-17. 1999b.

NYSTRÖM, C.; MALMQVIST, K. Comparison between the ring gap sizer and dry sieving. Acta Pharm. Suec., v.14, p.309-316, 1977.

NYSTRÖM, C.; STANLEY-WOOD, N. Measurement of particle size of free-flowing material with a ring gap sizer. Acta Pharm. Suec., v.13, p.277-284, 1976.

NYSTRÖM, C.; STANLEY-WOOD, N. Measurement of the minimum dimension of particles by a ring gap sizer. Acta Pharm. Suec., v.14, p.181-190, 1977.
PALMER, H.K.; ROWE, R.C. The application of mercury porosimetry to porous polymer powder. Powder Technol., v.9, p.1981-1986, 1974.

PENTLAND, A. A method of measuring the angularity of sands. Proceedings and transcription of the Royal Society of Canada, v. 21, p. 1927.

PODCZECK, F. Measurement of surface roughness of tablets made from polyethylene glycol powders of various molecular weights. Pharm. Pharmacol. Commun., v.4, p.179-182, 1998.

PODCZECK, F.; NEWTON, J.M. A shape fator to characterise the quality of spheroids.J. Pharm. Pharmacol., v.46, p.82-85, 1994.

PODCZECK, F.; NEWTON, J.M. The evaluation of a three-dimensional shape fator for the quantitative assessment of the sphericity and surface roughness of pellets. Int. J. Pharm., v.124, p.253-259, 1995.

PODCZECK, F.; RAHMAN, S.R.; NEWTON, J.M. Evaluation of a standardised procedure to assess the shape of pellets using image analysis. Int. J. Pharm., v.192, p.123-138, 1999.

RIIPPI, M.; ANTIKAINEN, O.; NISKANEN, T.; YLIRUUSI, J. The effect of compression force on surface structure, crushing strength, friability, and disintegration time of erythromycin acistrate tablets. Eur. J. Pharm. Biopharm., v.46, p. 339-345, 1998.

SALAKO, M.; PODCZECK, F.; NEWTON, J.M. Investigation into the deformability and tensile strength of pellets. Int. J. Pharm., v.168, p. 49-57. 1998.

SANTOS, H.; VEIGA, F.; PINA, M.; PODCZECK, F.; SOUSA, J. Physical properties of chitosan pellets produced by extrusion-spheronisation: influence of formulation variables. Int. J. Pharm., v.246, p.153-169, 2002.

SANTOS, H.; VEIGA, F.; PINA, M.; SOUSA, J. Compaction, compression and drug release characteristics of xanthan gum pellets of different compositions. Eur. J. Pharm. Sci., v.21, p.271-281, 2004. 
SANTOS, H.; VEIGA, F.; PINA, M.; SOUSA, J. Obtenção de pellets por extrusão e esferonização farmacêutica. Parte I. Avaliação das variáveis tecnológicas e de formulação. Rev. Bras. Cienc. Farm., v.40, p.455-470, 2004.

SANTOS, H.; VEIGA, F.; PINA, M.; SOUSA, J. Compaction, compression and drug release properties of diclofenac sodium and ibuprofen pellets comprising xanthan gum a a sustained release agent. Int. J. Pharm., v.295, p.15-27, 2005.

SCHNEIDERHÖHN, P. Eine vergleichende studie über methoden zur quantitativen bestimmung von abrundung und form an sandkörnern. Heidelb. Beitr. Miner. Petrogr., v.4, p.172-191, 1954.

SCHRÖDER, M.; KLEINEBUDDE, P. Structure of disintegrating pellets with regard to fractal geometry. Pharm. Res., v.12, p.1694-1700, 1995.

SHIPWAY, P.H.; HUTCHINGS, I.M. Fracture of brittle spheres under compression and impact loading: I Elastic stress distribution. Phil. Mag., v.A67, p.13891404, 1993.

TSUBAKI, J.; JIMBO, G. A proposed new characterization of particle shape and its application. Powder Technol., v.22, p.161-169, 1979.

VERTOMMEN, J.; ROMBAUT, R.; KINGET, R. Internal and external structure of pellets made in rotary processor. Int. J. Pharm., v.161, p.225-236, 1998.
YLIRUUSI, J.; HELLÉN, L.; MUTTONEN; E., MERKKU, P.; KRISTOFFERSON, E. Mathematical modelling of image analysis data of pellets. In: of the $11^{\text {th }}$ PHARMACEUTICAL TECHNOLOGY CONFERENCE, 11 ${ }^{\text {th }}$, Manchester, 1992. Proceedings. v.3, p. 53-62.

WAN, L.S.C.; HENG, P.W.S.; LIEW, C.V. Spheronization conditions on spheroids shape and size. Int. J. Pharm., v.96, p.59-65, 1993.

WAN, D.S.; JEYABALAN, T. A simple apparatus for measuring the crushing strength of pellets. Acta. Pharm. Technol., v.32, p.197-199, 1986.

WIKBERG, M.; ALDERBORN, G. Compression characteristics of granulated materials. II. Evaluation of granule fragmentation during compression by tablet permeability and porosity measurements. Int. J. Pharm., v.62, p.229$241,1990$.

WIKBERG, M.; ALDERBORN, G. Compression characteristics of granulated materials. VI. Pore size distributions, assessed by mercury penetration, of compacts of two lactose granulations with different fragmentation propensities. Int. J. Pharm., v.84, p.191-195, 1992.

ZUURMAN, K.; RIEPMA, K.A.; BOLHUIS, G.K.; VROMANS, H.; LERK, C.F. The relationship between bulk density and compactibility of lactose granulations. Int. J. Pharm., v.102, p.1-9, 1994.

Recebido para publicação em 15 de dezembro de 2004. Aceito para publicação em 04 de agosto de 2006. 